\title{
The Study Involving Partial Replacement of Slag Sand in Polymer Modified Concrete and its Application in Interlocking Concrete Paver Block (ICPB)
}

\author{
H. N. Umashankar ${ }^{1 *}$, B. V. Pramod ${ }^{2}$ \\ ${ }^{l}$ M.Tech. Student, Department of Construction Technology and Management, Dayananda Sagar College of \\ Engineering, Bengaluru, India \\ ${ }^{2}$ Assistant Professor, Department of Construction Technology and Management, Dayananda Sagar College of \\ Engineering, Bengaluru, India \\ *Corresponding author: umashankarp33@gmail.com
}

\begin{abstract}
The idea of Carriageway design and maintenance needs to be such that it bears loads due to the climate change and also for the social comfort which caters the all range of people who use the road way. In this study the potential of the paver blocks is evaluated in the laboratory. Styrene-Butadiene rubber induced paver blocks will have greater tension, good ductility and also, good impact strength because of the 3D polymer network. The bridging between cracks and also due to voids filling nature, the porosity decreases. A Styrene-Butadiene rubber polymer induced along with granular slag sand in ICPB to improve the ductility and flexure of polymer modified concrete (PMC). The structural properties of $\mathrm{PMC}$ in paver blocks are studied, the study is divided into two series, Series 1 is to cast paver blocks solely of granular slag sand and Series 2 is to cast paver blocks of PMC where fine aggregates with few parts replaced with Granular slag sand. The comparative study is done for various strength parameters. The study concludes that the paver blocks with PMC concrete with $15 \%$ of Granular slag sand replaced with fine aggregates.
\end{abstract}

Keywords: Compressive strength, Flexure strength, Interlocking Concrete Paver Blocks, Polymer modified concrete, Water absorption.

\section{Introduction}

The aggregate production is responsible for $50 \%$ of total greenhouse gas emissions for both asphalt and concrete pavements. Moreover, pavement networks are affected not only by traffic loading but also by environmental factors, such as ambient temperature and moisture. Therefore, pavement design methods should consider structural and other stresses stemming from the service condition. In addition to the service condition, the anthropogenic climate change imposes additional stresses that significantly influence the structural performance of the pavement during its life span. In this regard, the optimum life span and the mode and intensity of failures can change, which results in variations in the pavement management strategies, models of investment, and capital resource losses.
Polymers have good binding properties and good adhesion with aggregates. They have long-chain structure, which helps in developing long-range network structure of bonding. In reference, cement materials provide short-range structure of bonding. As a result, polymer materials usually provide greater compressive, tensile and flexural strength to the concrete compared to Portland cement. Some polymer materials may selectively provide higher compressive strength.

\section{Methodology and Materials}

\section{A. Methodology}

The SBR polymer is chosen for the polymer modified concrete. The basic tests for every material are done and the specifications is noted down. The mix proportion is arrived at using IS 10262-2019 and IRC SP63: 2004. The casting process for ICPB is divided into two series, Series 1 is cast with granular slag sand and Series 2 is cast with granular slag sand and polymer. The casting specification will be chosen from IS 15658:2006 for the particular application which is aimed at. The testing or Physical requirements for ICPB are divided into two types general and optional. The Series 1 mixes are evaluated through compressive strength and the mix which gives the satisfactory results is chosen for Series 2 where then the different proportions of polymer are experimented with to arrive at an optimum polymer proportion, for Series 2 the flexural strength is chosen as a base for evaluation.

\section{B. Materials and testing}

The Materials for conventional concrete's paver block are the M-sand, Coarse aggregate which is $10 \mathrm{~mm}$ down and $6 \mathrm{~mm}$ retained, Cement of grade 53, Superplasticizer $0.4 \%$ and Class F fly ash is used. The basic tests are done and found to be in limits as per Indian standards. The materials for Series 2 is a partial replacement of Granular slag sand with increments of 
$5 \%, 10 \% \ldots \ldots . .20 \%$. The materials for the Series 2 same as conventional concrete but the addition of an optimum proportion of granular slag sand and the polymer styrene butadiene rubber is used which should be in increments of 5, $10,15 \%$. The slump to check the workability of fresh concrete as specified by code IRC SP: 63:2004 should be between 25$50 \mathrm{~mm}$. the paver block which caters for (M-50) heavy vehicles are chosen to cast which has a thickness of $100 \mathrm{~mm}$.

\section{Mix Design}

The guidelines are given in IRC SP: 63:2004 is used to arrive at a mix design which gives the strength of $53 \mathrm{~N} / \mathrm{mm}^{2}$ for conventional concrete and the for series 1 it is just a partial replacement of Granular slag sand and for Series 2. Handbook for polymer modified concrete was referred which specifies to replace the polymer by cement.

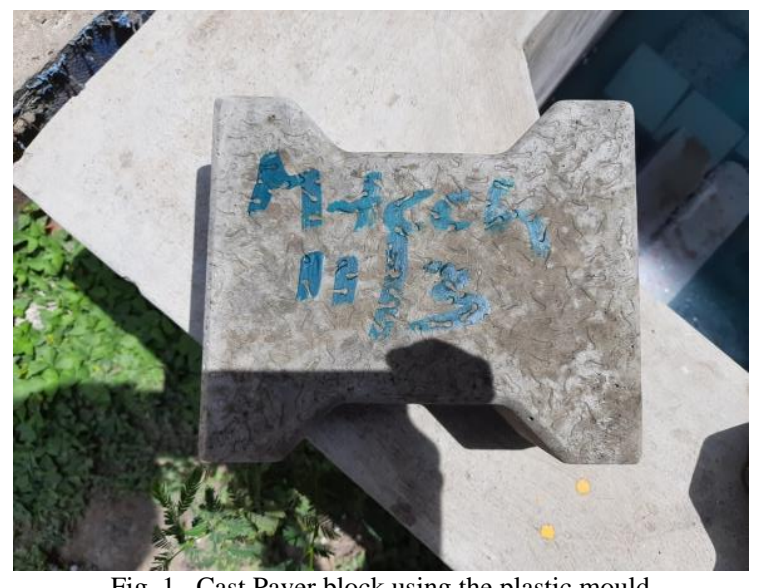

Fig. 1. Cast Paver block using the plastic mould

\section{Results and Discussion}

\section{A. Series 1 Mix}

The compressive strength is the base on evaluating an optimum proportion of granular slag sand. The graph below shows the trend for different proportions on the 14th day and 28th day. The graph shows that S3 is optimum hence the proportion of $15 \%$ is optimum for granular slag sand.

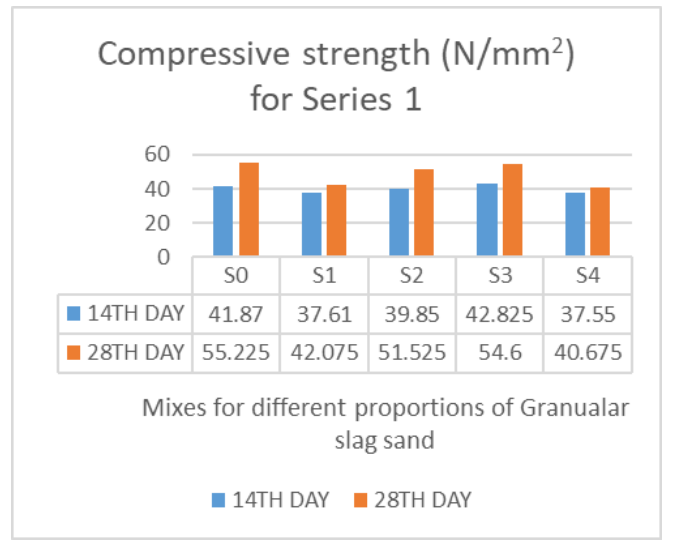

Fig. 2. Graph showing the variation in Compressive strength for different mixes of Series 1

\section{B. Series 2 Mix}

Here Flexural strength is the base for evaluating the optimum for the series 2 mix which is polymer modified concrete with partial replacement of granular Slag sand. The below graph shows the trend. The SP3 mix dominates in Flexural strength for paver block over other mixes in series 2 and also the conventional concrete.

Table 1

Flexural strength for conventional concrete

\begin{tabular}{|l|l|l|}
\hline \multirow{2}{*}{ Specimen (S0) } & \multicolumn{2}{|c|}{ Flexural strength $\left(\mathbf{N} / \mathbf{m m}^{2}\right.$ ) } \\
\cline { 2 - 3 } & 14th day & 28th day \\
\hline 1 & 3.50 & 5.23 \\
\hline 2 & 3.65 & 5.10 \\
\hline 3 & 3.12 & 4.92 \\
\hline 4 & 2.93 & 5.32 \\
\hline Avg. & 3.25 & 5.125 \\
\hline
\end{tabular}

Table 2

Flexural strength for Series 2 concrete with 15\% Polymer along with Slag sand

\begin{tabular}{|l|l|l|}
\hline \multirow{2}{*}{ Specimen (SP3) } & \multicolumn{2}{|c|}{ Flexural strength $\left(\mathbf{N} / \mathbf{m m}^{\mathbf{2}}\right)$} \\
\cline { 2 - 3 } & 14th day & 28th day \\
\hline 1 & 4.12 & 7.70 \\
\hline 2 & 4.35 & 7.63 \\
\hline 3 & 4.23 & 6.05 \\
\hline 4 & 4.92 & 7.92 \\
\hline Avg. & 4.405 & 7.325 \\
\hline
\end{tabular}

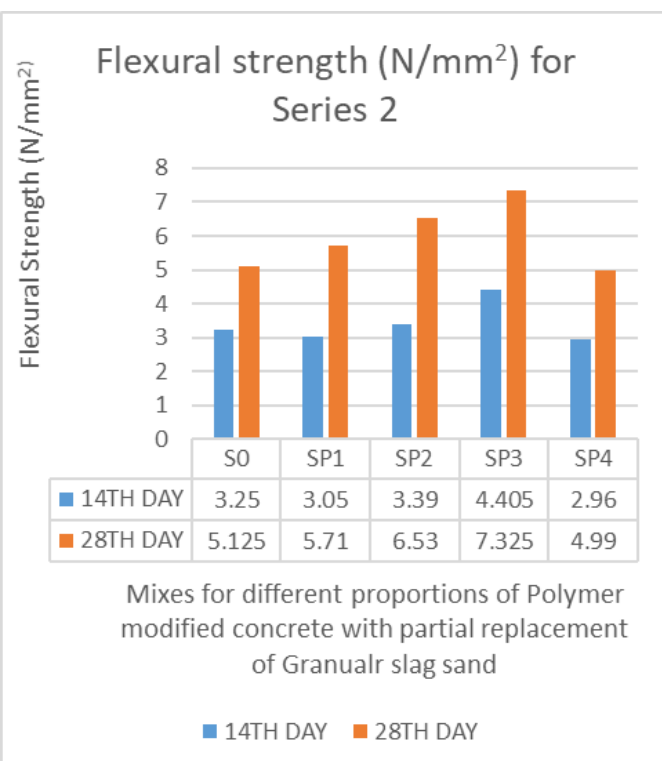

Fig. 3. Graph showing the variation in Flexural strength for different mixes of Series 2

C. Comparative study of SP3 Mix for compressive strength and water absorption with conventional concrete mix

\section{1) Compressive strength}

The comparative study for compressive strength shows there is no subsequent increase in strength which was found to be true in the literature survey. The graph below visualizes the same. 
Volume-3, Issue-10, October-2020

\section{IJRESM journals.resaim.com/ijresm | ISSN (Online): 2581-5792 | RESAIM Publishing}

Table 3

Compressive strength for conventional concrete

\begin{tabular}{|l|l|l|}
\hline \multirow{2}{*}{ Specimen (S0) } & \multicolumn{2}{|c|}{ Compressive strength $\left(\mathbf{N} / \mathbf{m m}^{2}\right)$} \\
\cline { 2 - 3 } & 14th day & 28th day \\
\hline 1 & 43.22 & 53.82 \\
\hline 2 & 39.21 & 56.8 \\
\hline 3 & 41.12 & 54.2 \\
\hline 4 & 44.20 & 56.1 \\
\hline Avg. & 41.87 & 55.225 \\
\hline
\end{tabular}

Table 4

Compressive strength for Series 2 concrete with 15\% Polymer along with Slag sand

\begin{tabular}{|l|l|l|}
\hline \multirow{2}{*}{ Specimen (SP3) } & \multicolumn{2}{|c|}{ Compressive strength $\left(\mathbf{N} / \mathbf{m m}^{2}\right.$ ) } \\
\cline { 2 - 3 } & 14th day & 28th day \\
\hline 1 & 42.42 & 54.12 \\
\hline 2 & 41.39 & 51.56 \\
\hline 3 & 40.58 & 50.92 \\
\hline 4 & 43.80 & 54.91 \\
\hline Avg. & 42.047 & 52.87 \\
\hline
\end{tabular}

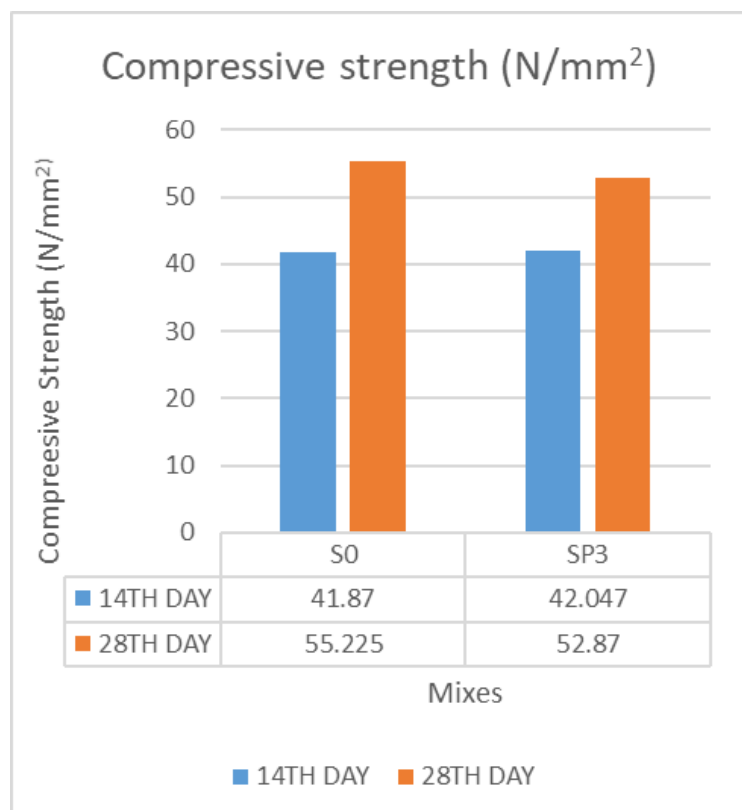

Fig. 4. Graph showing Comparative study of Compressive strength between the conventional concrete and the Series 2 mix of SP3

\section{2) Water absorption}

The water absorption for the polymer modified paver blocks is fewer compared to conventional concrete paver block that is it can be seen the value reduces from $5.78 \%$ to $5.203 \%$. The binding between the aggregate and cement intensifies so that less pores are present on the 28th day of the curing. Hence, less water absorption. The graph below specifies the same.

Table 5

Water absorption for conventional concrete

\begin{tabular}{|l|l|c|}
\hline \multirow{2}{*}{$\begin{array}{c}\text { Specimen (S0) } \\
\text { Conventional concrete }\end{array}$} & \multicolumn{2}{|c|}{ Water absorption (W\%) } \\
\cline { 2 - 3 } & 14th day & 28th day \\
\hline 1 & 5.89 & 5.82 \\
\hline 2 & 5.78 & 5.72 \\
\hline 3 & 5.99 & 5.82 \\
\hline Avg. & 5.88 & 5.78 \\
\hline
\end{tabular}

Table 6

Water absorption for Series 2 concrete with 15\% Polymer and 15\% of Slag sand

\begin{tabular}{|l|l|l|}
\hline \multirow{2}{*}{ Specimen (SP3) } & \multicolumn{2}{|c|}{ Water absorption (W\%) } \\
\cline { 2 - 3 } & 14th day & 28th day \\
\hline 1 & 5.76 & 5.26 \\
\hline 2 & 5.56 & 5.12 \\
\hline 3 & 5.63 & 5.23 \\
\hline Avg. & 5.65 & 5.203 \\
\hline
\end{tabular}

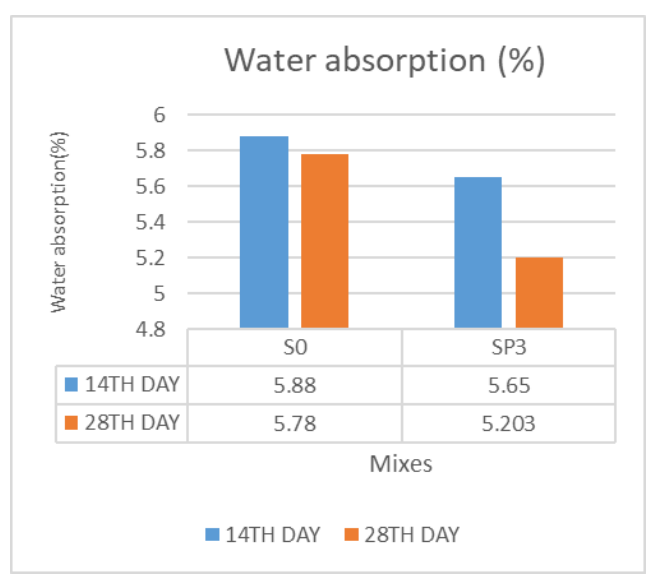

Fig. 5. Graph showing Comparative study of Water absorption between the Conventional concrete and the Series 2 mix of SP3

\section{Conclusion}

The above results give us hope to utilize the polymer modified concrete paver blocks for the roads that cater to the high volume of vehicles. The waste materials and alternative materials pave way for the reduction of carbon footprint set on the earth so that we could help prevent ills happening due to climate change. The SP3 mix that is polymer modified concrete with partial replacement of granular slag sand proves to be the ultimate mix which gives the better Flexural strength over other mixes. The availability of waste materials such as granular slag sand proves economical too. The polymer modified concrete is water repellent to some extent where, polymers are used to seal roads and other construction structures to protect from water. The main advantage of the ICPB is that it is durable if rehabilitated at right time. The self-healing property of polymer modified could also help in casting the durable paver blocks.

\section{References}

[1] IS 10262:2009: "Concrete Mix Proportioning - Guidelines", Bureau of Indian Standards Publications, New Delhi.

[2] IRC: SP 63-2004: "Guidelines for the Use of Interlocking Concrete Block Pavement", Bureau of Indian Standards Publications, New Delhi.

[3] IS 15658:2006: "Precast Concrete blocks for Paving- Specification", Bureau of Indian Standards Publications, New Delhi.

[4] IS 383:2016: "Coarse and Fine Aggregate for Concrete- Specification", Bureau of Indian Standards Publications, New Delhi.

[5] Yoshihiko Ohama, "Handbook of polymer-modified concrete and mortars properties and process technology."

[6] Ali Jamshidi, Kiyofumi Kurumisawa, Gregory White, Tatsuo Nishizawa, Toshifumi Igarashi, Toyoharu Nawa, Jize Maod, "State-of-the-art of interlocking concrete block pavement technology in Japan as a postmodern pavement," Construction building materials, 2019. 